\title{
Awareness of Periodontal Diseases and its Associated Adverse Pregnancy Outcomes among Pregnant Women attending a Tertiary Care Center
}

\author{
Junima Rajkarnikar,' Samriddhi Vaidya,' Jemish Acharya' \\ 'Department of Periodontics, CODSH, Nepal Medical College, Attarkhel, Jorpati, Nepal ${ }^{2}$ Department of Global Health, \\ Mahidol University, Bangkok, Thailand.
}

\section{ABSTRACT}

\section{Introduction:}

Periodontal diseases are associated with high levels of gram-negative periodontal pathogens that apparently increase abundantly in the presence of pregnancy-associated hormones. Endotoxins from gram-negative bacteria enter the circulation at high levels to stimulate the production of inflammatory mediators, such as prostaglandins and other inflammatory mediators which are potent inducers of labor. The present study was conducted to assess oral health awareness and experience among pregnant women attending a tertiary care hospital.

\section{Methods:}

A cross-sectional study was conducted in 167 pregnant women visiting a tertiary care center using self- administered structured questionnaire consisting of questions related to knowledge and awareness regarding periodontal diseases and its possible associated adverse pregnancy outcomes.

\section{Results:}

Of the total participants, $55.7 \%$ said that they did not think gum disease can have adverse pregnancy outcomes. Only $35.9 \%$ had, at some point, consulted a dentist for bleeding gums and $36.5 \%$ of them had gingival enlargement during pregnancy but $46.1 \%$ said that they should wait for the delivery before they could do any dental treatment. Also, 40.1\% did not know the safe trimester to undergo dental treatment and only $20.4 \%$ said the second trimester was the safest to undergo any dental procedure.

\section{Conclusion:}

The study showed that awareness and knowledge of periodontal health among pregnant women was not satisfactory.

Keywords: Awareness; adverse pregnancy; periodontal disease; pregnancy outcomes.

Correspondence: Dr. Junima Rajkarnikar, Associate Professor and Department Head, Department of Periodontics, CODSH, Nepal Medical College, Attarkhel, Jorpati, Nepal.Email: drjunima@gmail.com. Phone: +977-9851170767 


\section{INTRODUCTION}

Periodontal diseases are attributed to interactions between the host immunity and multiple microbial species, including multiple gram-negative microaerophilic and anaerobic bacteria like Porphyromoas gingivalis, Fusobacterium nucleatum, Prevotella intermedia, Aggregatibactor actinomycetemcomitans, Treponemadenticola, etc. in the subgingival environment. ${ }^{1}$ Microbiological studies have shown that estrogen and progesterone changes associated with pregnancy affects the composition of the subgingival microbiota. ${ }^{2,} 3$ Some of the periodontal pathogens that apparently increase abundantly in the presence of pregnancyassociated hormones are Prevotella intermedia, Bacteroides species and Campylobacter rectus. ${ }^{4}$

Endotoxins from gram-negative bacteria enter the circulation at high enough levels to stimulate the production of inflammatory mediators, such as prostaglandin E2, ${ }^{5}$ which are potent inducers of labor. Studies have also found that periodontal therapy resulted in a significant reduction in adverse pregnancy outcomes. ${ }^{6,7}$ If periodontal infections are truly important in the pathogenesis of adverse pregnancy outcomes, treatment of these infections should reduce the incidence of these outcomes. ${ }^{7}$

The present study aims to assess oral health awareness and experience among pregnant women attending a teaching hospital. The objective of the study is to create awareness of the importance of oral health in pregnancy and to encourage pregnant ladies to visit dental clinics during pregnancy.

\section{METHODS}

This is a cross-sectional questionnaire study, done on the patients who came to the Department of Obstetrics and Gynecology, at Nepal Medical College Teaching Hospital, Attarkhel, Nepal during the time of November- December 2020. The data was collected based on knowledge and behavioral aspects which was derived from a series of independent questionnaires. Those who were having any systemic illnesses like diabetes and HIV and who were uncooperative or not willing to give consent were excluded from the study.

Participation in the survey was voluntary and anonymity was maintained about the personal record. Ethical clearance was obtained from the Nepal Medical College Institutional Review Committee (IRC).

The questionnaire consisted of questions which were divided into four parts;

The questions assessing the demographic characteristics

Questions on daily oral health practices

Knowledge about changes in oral health during pregnancy

Awareness about oral health and pregnancy outcomes.

Using the Cochran statistical formula $\left(\mathrm{N}=\mathrm{Z}^{2} \mathrm{Pq} /\right.$ $\mathrm{d}^{2}$ ), the minimum sample size for the study was 164 where $Z=95 \%$ confidence interval, $P$ (the prevalence of pregnant women with good knowledge) was set at $30 \%$, q was equal to 1 $\mathrm{P}$, and $\mathrm{d}$ is a minimum acceptable degree of error which is set at 5\%. Purposive sampling was done. Statistical analysis was done using SPSS version 20. So the minimum sample size for the study was 164 .

\section{RESULTS}

In our study, the maximum age group was in the range of $20-29$ years (65.9\%) and since Jorpati is a village, probably $44.3 \%$ of the participants were educated only till primary school and $56.9 \%$ of them were housewives (Table 1). There were also $16.8 \%$ who were educated till the bachelor's degree and $4.2 \%$ of them had completed a master's degree. 


\begin{tabular}{|l|l|l|}
\hline \multicolumn{3}{|l|}{ Table 1. Socio-demographic characteristics. } \\
\hline Education & Frequency & Percentage \\
\hline No formal education & 10 & $6 \%$ \\
\hline Primary school & 74 & $44.3 \%$ \\
\hline High school certificate & 48 & $28.7 \%$ \\
\hline Bachelor's degree & 28 & $16.8 \%$ \\
\hline Post graduate & 7 & $4.2 \%$ \\
\hline Age group & & \\
\hline $16-20$ years & 26 & $15 \%$ \\
\hline $20-29$ years & 110 & $65.9 \%$ \\
\hline $30-39$ years & 31 & $18.6 \%$ \\
\hline Occupation & & \\
\hline Housewife & 95 & $56.9 \%$ \\
\hline Government job & 6 & $3.6 \%$ \\
\hline Private job & 31 & $18.6 \%$ \\
\hline Self employed & 35 & $21 \%$ \\
\hline
\end{tabular}

Regarding the frequency of brushing, $75.4 \%$ confirmed that they brushed once a day. There were also $1.8 \%$ who revealed that they did not brush during pregnancy (Table 2). Surprisingly, $73.1 \%$ of pregnant women have never undergone oral prophylaxis (Table 2).

Table 2. Oral hygiene awareness and practices.

\begin{tabular}{|l|l|l|}
\hline Brushing frequency & Frequency & Percentage \\
\hline Once daily & 126 & $75.4 \%$ \\
\hline Twice daily & 38 & $22.8 \%$ \\
\hline No brushing & 3 & $1.8 \%$ \\
\hline
\end{tabular}

Last time when scaling was done in dental hospital /clinic

\begin{tabular}{|l|l|l|}
\hline 6 months back & 6 & $3.6 \%$ \\
\hline 1 year back & 4 & $2.4 \%$ \\
\hline More than 1 year back & 15 & $9 \%$ \\
\hline Don't remember & 20 & $12 \%$ \\
\hline Never done & 122 & $73.1 \%$ \\
\hline
\end{tabular}

Of the total participants, $55.7 \%$ said that they did not think gum disease can have adverse pregnancy outcomes (Table 3). Also, 44.3\% currently had bleeding from gingiva while brushing but only $35.9 \%$ had, at some point, consulted a dentist for bleeding gums (Table 3). Upon asking about any history of gingival enlargement during any of their pregnancies, $36.5 \%$ of them were affirmative and $46.1 \%$ said that they should wait for the delivery before they could do any dental treatment (Table 3).

Table 3. Knowledge on periodontal health and pregnancy.

\begin{tabular}{|c|c|c|c|}
\hline Variable & Response & Frequency & Percentage \\
\hline \multirow{2}{*}{$\begin{array}{l}\text { Do you think gum diseases } \\
\text { have adverse pregnancy } \\
\text { outcomes }\end{array}$} & Yes & 74 & $44.3 \%$ \\
\hline & No & 93 & $55.7 \%$ \\
\hline \multirow{2}{*}{$\begin{array}{l}\text { Do you have bleeding } \\
\text { gums while brushing }\end{array}$} & Yes & 74 & $44.3 \%$ \\
\hline & No & 93 & $55.7 \%$ \\
\hline \multirow{2}{*}{$\begin{array}{l}\text { Have you consulted a } \\
\text { dentist for bleeding gums }\end{array}$} & Yes & 60 & $35.9 \%$ \\
\hline & No & 107 & $64.1 \%$ \\
\hline \multirow{2}{*}{$\begin{array}{l}\text { Do you have gum } \\
\text { enlargement / history of } \\
\text { gum enlargement in any } \\
\text { of your pregnancies? }\end{array}$} & Yes & 61 & $36.5 \%$ \\
\hline & No & 106 & $63.5 \%$ \\
\hline \multirow{2}{*}{$\begin{array}{l}\text { Do you think you should } \\
\text { wait for your delivery } \\
\text { before you could visit a } \\
\text { dentist for your treatment }\end{array}$} & Yes & 77 & $46.1 \%$ \\
\hline & No & 90 & $53.9 \%$ \\
\hline
\end{tabular}

Regarding knowledge on safe trimester to undergo dental treatment during pregnancy, $40.1 \%$ did not know the answer and only $20.4 \%$ said the second trimester was the safest to undergo any dental procedure (Figure 1).

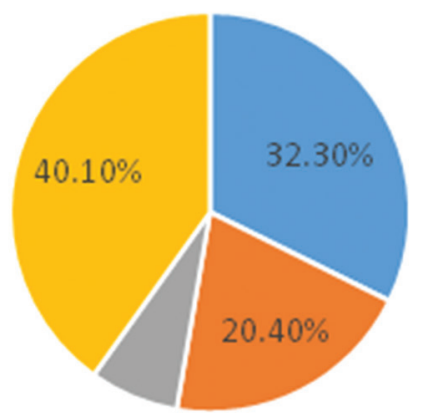

1st trimester

a 2nd trimester

- 3rd trimester

do not know

Figure 1. Safe trimester to perform dental treatment. 


\section{DISCUSSION}

In our study, the majority of the participants were educated till primary school $(44.3 \%)$ and only $4.2 \%$ were educated till the master's level. In a similar study done in a rural population of Zambia, $60 \%$ of the participants had no education or educated only till the primary level. ${ }^{8}$ Maximum participants in our study were in the age group 20-29 years (65.9\%). In a similar study done with age ranging from 15 to 43 years, the median age was 24 years. ${ }^{8}$ In another study also the majority of the participants were in the age group of 21-25 years. ${ }^{9}$ One study showed that $36 \%$ of the participants were in the age group of 21-26 years which was the maximum number in any age group taken. ${ }^{10}$ These similar data shows that most of the pregnant women were in their twenties.

Our study comprised of 56.9\% housewives which were in concordance to another study which comprised of $93 \%$ housewives. ${ }^{10}$

Our study showed that $75.4 \%$ of the participants brushed once a day whereas $1.8 \%$ did not practice brushing in their pregnancy. This was similar to a study in which about $94 \%$ of the women were brushing their teeth at least once a day. ${ }^{11} \mathrm{~A}$ similar study showed that around $18.6 \%$ did not brush their teeth during pregnancy although reasons were not clear. ${ }^{12}$ One study showed that $8.0 \%$ did not practice brushing during pregnancy. ${ }^{9}$

It could be due to pregnancy complication like nausea or due to a myth that one should not brush during pregnancy as shown by a study in which $42.0 \%$ said they had difficulty in oral hygiene maintenance during pregnancy. ${ }^{9}$ Another study showed that only $34.80 \%$ clean their teeth twice daily which is similar to our study in which $22.8 \%$ brushed twice daily. ${ }^{13}$

Regarding the answer to the last time when scaling was done in a dental hospital/clinic, only $3.6 \%$ had undergone oral prophylaxis 6 months back and $73.1 \%$ who has never done oral prophylaxis in their life. Also, 64.1\% has never visited a dentist for bleeding gums. Similar to our study, one questionnaire study showed that $100 \%$ of the lower middle class had never visited a dental clinic. ${ }^{14}$ Another study showed that only $2.9 \%$ visited a dentist, that too more than 6 months back. ${ }^{10}$ A study conducted in India showed that $93.9 \%$ of pregnant women did not go for routine dental check-ups. ${ }^{15}$ Another study had similar results as only $13.7 \%$ visited a dentist during their pregnancy. ${ }^{16}$ Similar study showed $15 \%$ of participants never visited the dentist. ${ }^{17}$

Nearly $72.81 \%$ of pregnant females had never attended the dentist. ${ }^{18}$

In our study, upon questioning whether they thought the gingival disease could have an adverse pregnancy outcome, $55.7 \%$ said it did not have any significant effect. One of the studies revealed that $99 \%$ of their participants felt there was no relation between priodontal diseases $\mathrm{n}$ preterm baby. ${ }^{14}$ Another study revealed that $5.1 \%$ believed there might be a relationship between gum diseases and premature labor. ${ }^{19}$ Also one study showed that $60 \%$ of pregnant women had low awareness regarding pregnancy and periodontal disease. ${ }^{10}$ In another study, 95\%were not aware that gum disease could cause preterm low birth weight babies. ${ }^{18}$

In our study, $44.3 \%$ experienced bleeding from gingiva although $64.1 \%$ of the participants never consulted a dentist. Similar study showed 32.7\% experienced gum bleeding during pregnancy. ${ }^{20}$ In our study, 36.5\% experienced gingival enlargement or they had a history of gingival enlargement during their previous pregnancies and $46.1 \%$ of them thought they had to wait till the delivery before they could visit a dentist for any treatment. A similar study showed that $23.5 \%$ of the participants had gingival enlargement. ${ }^{20}$ 
Our study also showed that $40.1 \%$ did not know the safe trimester to undergo dental treatment during pregnancy which was in concordance with a study where $93 \%$ were not aware of the safe period for undergoing dental treatment during pregnancy. ${ }^{18}$

Another study showed only 3\% of pregnant women being aware of oral health having a correlation with adverse pregnancy outcomes which also showed that $96 \%$ of women had received no knowledge from the gynecologist regarding the impact of oral health on pregnancy outcomes. ${ }^{15}$

The American Dental Association (ADA) suggests that during the first and third trimester of pregnancy, elective dental care should be avoided, if possible. ${ }^{21}$ California Dental Association Foundation states that the use of dental $x$-rays and local anesthesia for prevention, diagnosis, and treatment of oral diseases, are highly beneficial with no additional fetal or maternal risk. ${ }^{22}$

Physicians should have adequate knowledge about the association between pregnancy and oral health. In a study conducted, only $40 \%$ gynecologists recommended dental examination

\section{REFERENCES}

1. George A, Shamim S, Johnson M. Periodontal treatment during pregnancy and birth outcomes: A meta-analysis of randomised trials. Int J Evid Based Health 2011; 9: 122-147.

2. Jensen J, Liljemark W, Bloomquist C. The effect of female sex hormones on subgingival plaque. J Periodontol 1981: 52: 599-602.

3. Kornman KS, Loesche WJ. The subgingival microbial flora during pregnancy. J Periodontal Res 1980: 15: 111-122. during pregnancy although more than $70 \%$ of respondent obstetricians correctly knew of the effects of periodontitis on preterm birth and low birth weight babies. ${ }^{23}$

Also a community based study conducted in Sarlahi district of Nepal stated that the cost factor was the reason for not seeking dental care during pregnancy. In this study $40 \%$ of the participants had signs of clinical gingivitis and $88 \%$ had never received oral health care. ${ }^{24}$

\section{CONCLUSIONS}

Our study shows that the knowledge of importance of oral health in pregnancy outcomes is not satisfactory among pregnant women visiting this tertiary care center. The provision of oral health education and necessary referral during antenatal care is essential for the benefit of pregnant women.

\section{ACKNOWLEDGEMENTS}

We would like to express our sincere gratitude to Dr. Pramila Pradhan, Head of Department of Obstetrics and Gynaecology of Nepal Medical College Teaching Hospital for giving us opportunity to carry out the study.

4. Yokoyama M, Hinode D, Yoshioka M, Fukui M, Tanabe S, Grenier D, et al. Relationship between Campylobacter rectus and periodontal status during pregnancy. Oral MicrobiolImmunol 2008: 23: 55-59.

5. Klebanoff $M$, Searle $K$. The role of inflammation in preterm birth - focus on periodontitis. Br J ObstetGynaecol 2006: 113(Suppl. 3): 43-45.

6. Lopez NJ, Smith PC, Gutierrez J. Periodontal therapy may reduce the risk of preterm low birth weight in women 
with periodontal disease: a randomized controlled trial. J Periodontol 2002: 73: 911-924.

7. Lopez NJ, Da Silva J, Ipinza J, Gutierrez J. Periodontal therapy reduces the rate of preterm low birth weight in women with pregnancy-associated gingivitis. J Periodontol 2005: 76: 2144-2153.

8. Kabali, T. M., \&Mumghamba, E. G. (2018). Knowledge of Periodontal Diseases, Oral Hygiene Practices, and Self-Reported Periodontal Problems among Pregnant Women and Postnatal Mothers Attending Reproductive and Child Health Clinics in Rural Zambia. International Journal of Dentistry, 2018, 978209.

9. Rajesh KS, Ashif A, Hedge S, Arun Kumar MS. International Journal of Applied Dental Sciences 2018; 4(1): 138-142.

10. Ibrahim H.M. El-Mahdi, Mudawi A.M, Ghandour I.A. Oral health status, knowledge and practice among pregnant women attending Omdurman maternity hospital, Sudan. EMHJ 2016;22:802-9.

11. Hashim R. Self-reported oral health, oral hygiene habits and dental service utilization among pregnant women in United Arab Emirates. Int J Dent Hygiene. 2012;10:142-146.

12. ParappaS, Jyoti I P, Chiyadu P, Veeresh M N , Mangala S, Taha S. Oral Health Related Awareness And Practices Among Pregnant Women In Bagalkot District, Karnataka, India. J Int Oral Health 2015;7:1-5.

13. Barge P, Kamala K, Sankethguddad S, NayakA, Ashwini S, Sanade A. Oral Health Status, knowledge and practices among pregnant women - A Questionnaire Study. EJBPS 2017;4:455-59.

14. Ramamurthy J, Irfana F. Assessment of knowledge and awareness about periodontal oral health among pregnant women- a questionnaire study. IJCRR 2017;09: 9-12.

15. Gupta S, Jain A, Mohan S, Bhaskar N, Walia P. Comparative evaluation of oral health knowledge, practices and attitude of pregnant and non-pregnant women, and their awareness regarding adverse pregnancy outcomes. J Clin Diagn Res. 2015; 9:26-32.

16. Bugra $\mathrm{O}$, Levent $\mathrm{O}$, Feridun $\mathrm{B}$, Ceyhan A, Cengizhan A. Turkish Women's SelfReported Knowledge And Behavior Towards Oral Health During Pregnancy. Med Princ Pract2012;21:318-322.

17. Nishana FK, Shetty S, Manjunath N, Damodaran D.Assessment of Knowledge, Attitude, Practice, Awareness Level of Periodontal Health and Adverse Outcomes among Pregnant Women - A Questionnaire Study. Int J of Innov Sci and Res Techno 2018;3:820-26.

18. Leelavathi L, Merlin T, Ramani V, Suja $\mathrm{R}$, Chandran C. Knowledge, attitude, and practices related to the oral health among the pregnant women attending a government hospital, Chennai. Int J Community Dent 2018;6:16-20.

19. Alwaeli HA, JundiSH. Periodontal disease awareness among pregnant women and its relationship with socio-demographic variables. IntJ Dent Hyg. 2005;3(2):74-82.

20. Bashiru BO, Anthony IN. Oral health awareness and experience among pregnant women in a Nigerian tertiary 
health institution. J Dent Res Rev 2014;1:66-9.

21. Gaffield ML, Brenda J, Gilbert C, Malvitz DM, Romaguera MR. Oral health during pregnancy An analysis of information collected by the Pregnancy Risk Assessment Monitoring System. J Am Dent Assoc. 2001; 132(7):1009-1016.

22. CaliforniaDentalAssociation Foundation; American College of Obstetricians and Gynecologists, District IX. Oral health during pregnancy and early childhood: evidence-based guidelines for health professionals. J Calif Dent Assoc.
2010 Jun;38(6):391-403, 405-40. PMID: 20645626.

23. Suri V, Rao Nc, Aggarwal N. A study of obstetricians' knowledge, attitudes and practices in oral health and pregnancy. Educ health 2014;27:51-4.

24. Erchick, D. J., Rai, B., Agrawal, N. K., Khatry, S. K., Katz, J., LeClerq, S. C., Reynolds, M. A., \&Mullany, L. C. (2019). Oral hygiene, prevalence of gingivitis, and associated risk factors among pregnant women in Sarlahi District, Nepal. BMC Oral Health, 19(1), 2.

Citation: Rajkarnikar J, Vaidya S, Acharya J. Awareness of Periodontal Diseases and its associated Adverse Pregnancy Outcomes Among Pregnant Women Attending a Tertiary Care Center. JCMS Nepal. 2021; 17(3); $213-19$. 